\title{
Diagnosis and interrelationships of fishes of the genus Channa Scopoli (Teleostei: Channidae) of northeastern India
}

\author{
W. Vishwanath ${ }^{1} \&$ Kh. Geetakumari ${ }^{2}$ \\ 1,2 Department of Life Sciences, Manipur University, Canchipur, Manipur 795003, India \\ Email: ${ }^{1}$ wvnath @ gmail.com; ${ }^{2}$ geetamene @ gmail.com
}

\begin{abstract}
Diagnostic characters of nine species of the genus Channa Scopoli of northeastern India are given. Examination of morphological and osteological characters revealed that the fish under study comprised two phylectic groups: marulius and gachua. The Marulius group is characteristic by having a very prominent $\mathrm{V}$-shaped sharp isthmus, cephalic sensory pores arranged in groups, absence of scales on the lower jaw, a sharp prominent spinelike hypurapophysis, more branchial toothplates than epibranchial, and an elongated urostyle. The Gachua group is characterized by a U-shaped isthmus, cephalic sensory pores evenly arranged in a single row, the presence of one or two large cycloid scales on each side of the lower jaw, absence of a sharp prominent spine-like hypurapophysis, absence or presence of one tooth plate in the epibranchial, and absence of an elongated urostyle. An elongated bone is present in between two last hemal spines of all species examined. A key to known species of Channa of northeastern India is also given
\end{abstract}

Keywords: Channa, diagnosis, interrelationship, northeastern India

Abbreviations: MUMF - Manipur University Museum of Fish; GUMF - Guwahati University Museum of Fish

Date of online publication 26 February 2009 ISSN 0974-7907 (online) | 0974-7893 (print)

Editor: Rema Dev

Manuscript details:

Ms \# 01788

Received on 24 May 2007

Final revised received 28 March 2008

Finally accepted 30 March 2008

Citation: Vishwanath, W. \& Kh. Geetakumari (2009). Diagnosis and interrelationships of fishes of the genus Channa Scopoli (Teleostei: Channidae) of northeastern India. Journal of Threatened Taxa 1(2): 97-105.

Copyright: () W. Vishwanath \& Kh. Geetakumari 2009. Creative Commons Attribution 3.0 Unported License. JoTT allows unrestricted use of this article in any medium for non-profit purposes, reproduction and distribution by providing adequate credit to the authors and the source of publication.

Author Details: See end of article

Author contributions: See end of article

Acknowledgements: The authors are grateful to Prof. M.M. Goswami, Department of Zoology, Guwahati University for valuable informations and also granting permission to access his valuable collections; to Dr. D.N. Das, Head, Department of Zoology, Rajiv Gandhi University, Itanagar for valuable help and to Director, ZSI for permission to examine fish specimens. The second author (Kh. G.) records her thankfulness to Manipur University for grant of research fellowship. The first author is grateful to Ministry of Environment \& Forests, Govt. of India for research grant No. 14/11/2006-ERS/RE
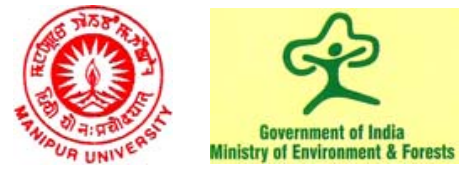

OPEN ACCESS | FREE DOWNLOAD

\section{INTRODUCTION}

Genus Channa Scopoli, 1777 of the family Channidae is distinguished from other genera of the family in having long, soft dorsal and anal fins, scales on the head mostly cycloid and that on the body, mostly ctenoid, caudal fin rounded, curved lateral line. The genus is also characterized by a suprapharyngeal accessory respiratory organ which facilitates an air-breathing mode of life. Northeastern India is rich in swamps and lakes, and in Channid fauna. Under the All India co-ordinated project on air breathing fishes, Dehadrai (1975) made extensive studies on the cage culture of some of the species of this region. However, taxonomy and phylogeny of the Channid fishes of the region is poorly understood.

The Channidae are represented by 26 species, of which 23 occur in Asia and the rest in Africa (Musikasinthorn 2000). Hamilton (1822) described Ophiocephalus barca (now Channa) from Brahmaputra river near Goalpara, Assam. Hora (1921) listed C. punctatus (Bloch) from Chindwin basin, Manipur. Shaw and Shebbeare (1937) listed and gave brief descriptions of six species from northern Bengal, viz, C. amphibeus (McClelland), C. gachua (Hamilton), C. marulius (Hamilton), C. stewartii (Playfair) and C. striata (Bloch). Later reports on the fishes of Manipur by Menon (1952), and Menon (1954) did not include additional species of the genus. Sen (1985) listed and gave diagnostic characters of six species of the genus. Vierke (1991) described C. bleheri from Assam.

Musikasinthorn (2000) described Channa aurantimaculata from Dibrugarh, Assam. Vishwanath's (2000 \& 2002) works respectively on the fishes of Manipur and northeastern India did not include any additional species. Thus nine species of Channa are known from northeastern India.

In the present study, detailed morphology and osteology of nine species, viz., Channa amphibeus, C. aurantimaculata, C. barca, C. bleheri, C. gachua, C. marulius, C. punctatus, C. stewartii and C. striata were carried out. Diagnostic characters and interrelationships of the species are presented here. A key to identification of the known species of Channa of the region is also included.

\section{Materials and Methods}

Fresh specimens were collected from different fishing sites of northeastern India. Measurements and counts followed Kullander and Britz (2002). Cleared and stained specimens were used for osteological studies. Clearing and staining of specimens followed Hollister (1934). Radiographs were taken using DX-300 X-ray machine and developed digitally using Centricity CR SP100, and used for vertebral count in species for which limited specimens were available. Identification and nomenclature of bones as well as vertebral counts followed Greenwood (1976). For branchial tooth plate count, the first 
gill arch of the left side of the specimens was taken. Plates starting from hypobranchial to epibranchial of the outer side were counted

\section{Channa amphibeus (McClelland) (Image 1)}

Ophicephalus amphibeus McClelland 1845: 274-279 (type locality: vicinity of Chail River, one of the tributaries of the Teesta at the foot of the Bouton mountains).

Materials examined: 1 ex., (date unknown), 184.6mm SL, northern Bengal, India, coll. G.E. Shaw \& E.O. Shebbeare, ZSI F 11435/1, neotype designated by P. Musikasinthorn 2000.

Distribution: Chel River basin, in the Brahmaputra River drainage of northeastern India and Bhutan.

Diagnosis: A species of Channa with lateral line scales 81 , predorsal scales 17, maxilla extending beyond the posterior margin of eye, circumpeduncular scales 31 , cephalic sensory pores single, two large scales, two large scales on each side of lower jaw under surface dorsal fin rays 50, anal fin rays 35 , pectoral fin rays 15 , pelvic fin rays six, cheek scales nine, body depth greatest at insertion of anal fin, body width greatest at insertion of pectoral fin. Snout somewhat pointed in dorsal view. Orbit not reaching dorsal contour of head in lateral view, upper and lower lips flattened.

Colour: In alcohol: body uniformly light brown, ventral surface whitish. Eleven vertical brown bars on upper half of body, extending below lateral line. Edges of dorsal, anal and caudal fins whitish.

Remarks: Diagnosis based on neotype and Shaw \& Shebbeare (1937).

\section{Channa aurantimaculata Musikasinthorn (Image 2)}

Channa aurantimaculata, Musikasinthorn, 2000: 27. (type locality: streams near Dibrugarh town, Dibrugarh, Assam)

Materials examined: 2 exs., 29.i.2007, 121.9-131.2mm SL, Teju River, Teju district, Arunachal Pradesh, India, coll. K. Nebeshwar, MUMF-Per/0001; 3 exs., 17.xii.2006, 125-130mm SL, Dibrugarh, Assam, India, (coll. unknown), GUMF uncat.

Distribution: India: Teju River, Arunachal Pradesh; Brahmaputra river basin at Dibrugarh, northern Assam.

Diagnosis: A species of Channa with lateral line scales 5154 , dorsal fin rays $45-47$, anal fin rays $28-30$, mouth large, eyes moderate, caudal fin rounded, cheek scales 8-12, upper jaw length more than $45 \%$ HL, 3-4 bars on the pectoral fin, pectoral fin rays 14-16, two large cycloid scales on each side of the lower jaw undersurface, pelvic fin length less than half the pectoral fin length, cephalic sensory pores single, maxilla extending clearly beyond posterior margin of eye, total vertebrae count 51 (Image 3), branchial tooth plate count 6 .

Colour: Upper half of body dark brown to black with 7 or 8 large irregular orange blotches; pectoral fins with a black blotch at base and 5 vertical broad vivid black bands.

Remarks: It is endemic to Brahmaputra River basin. The report extends its distribution to Arunachal Pradesh.

\section{Channa barca (Hamilton)}

(Image 4)

Channa barca Hamilton, 1822:67, 367. (type locality: Brahmaputra R. near Goyalpara, Assam, India)
Materials examined: 1 ex., 6.v.2007, 295mm SL, Fringe area of Pobitora wildlife Sanctuary, Morigaon, Assam, India, coll. M.M. Goswami, MUMF-Per/0044; 3 exs., same data as above, 295.3-297.0mm SL, GUMF uncat.

Distribution: India. Bangladesh (Eschmeyer 2007)

Diagnosis: A species of Channa with lateral line 62-63, dorsal fin rays 50-51, anal fin rays 33-34, mouth large, caudal fin rounded, scales above the lateral line 5.5-6.5, predorsal scales 15-16, cephalic sensory pores single, two large cycloid scales on each side of the lower jaw undersurface, caudal fin rounded, total vertebrae count 56 .

Colour: Dorsal and flanks covered with numerous black spot, pectorals reddish with numerous black spots.

Remarks: The species is burrowing in habit, and lives in vertical burrows (Goswami et al. 2006).

\section{Channa bleheri Vierke (Image 5)}

Channa bleheri Vierke, 1991:22. (type locality: Assam).

Material examined: 1 ex., 29.i.2007, 149.1mm SL, Dikrong River, Doymukh, Arunachal Pradesh, India, coll. K. Nebeshwar, MUMF-Per/0003; 1 ex., 6.xii.2006, 148.4mm SL, streams near Dibrugarh market, Assam, India, coll. M.M. Goswami, GUMF.

Distribution: India: Assam, Brahmaputra basin, Arunachal Pradesh

Diagnosis: A species of Channa with a slightly broad head, pelvic fin absent, sides of lower jaw have one large cycloid scale, 4-11 red or orange markings on caudal fin, eyes moderate, and caudal fin rounded, mouth large, 6-7 markings on the pectoral fin, maxilla and premaxillary processes extending beyond the posterior margin of the orbit, snout blunt, cephalic sensory pores single, lateral line complete with 46-50 scales, anal fin rays 25 and pectoral fin rays 14, total vertebral count 43 , branchial toothplate count five. Tooth plates are present only on the outer side of the first gill arch and absent on the inner side of the same arch.

Colour: Grey to brown on sides, pale yellow to white ventrally, pectoral fin with 7 to 8 bars of alternating black and white bars.

Remarks: The report extends its distribution to Arunachal Pradesh.

\section{Channa gachua (Hamilton) (Image 6)}

Ophicephalus gachua, Hamilton, 1822:68, 367. (type locality: Ponds and ditches of Bengal)

Materials examined: 8 exs., 3.iii.2004, 112.8-112.9mm SL, Nambul River, Singda, Manipur, India, coll. S. Sanjabihari, MUMF-Per/0004; 3 exs., 29.i.2007, 112.8-112.82mm SL, Deopani River, Rowang, Lower Devang valley District, Arunachal Pradesh, India, coll. K. Nebeshwar, MUMF-Per/ 0046 .

Distribution: Afghanistan in the west to Indonesia through South and Central Asia (Eschmeyer 2007)

Diagnosis: A species of Channa with dorsal fin rays 32-37; lateral line scales $39-48$, pelvic fin shorter than half the pectoral fin length, pectoral fin rays $15-17$, 'anal fin rays $21-27$, and caudal fin rays 12 , maxilla and premaxillary process extending to vertical level of the posterior end of the orbit, one or two large cycloid scale on each side of lower jaw undersurface, 


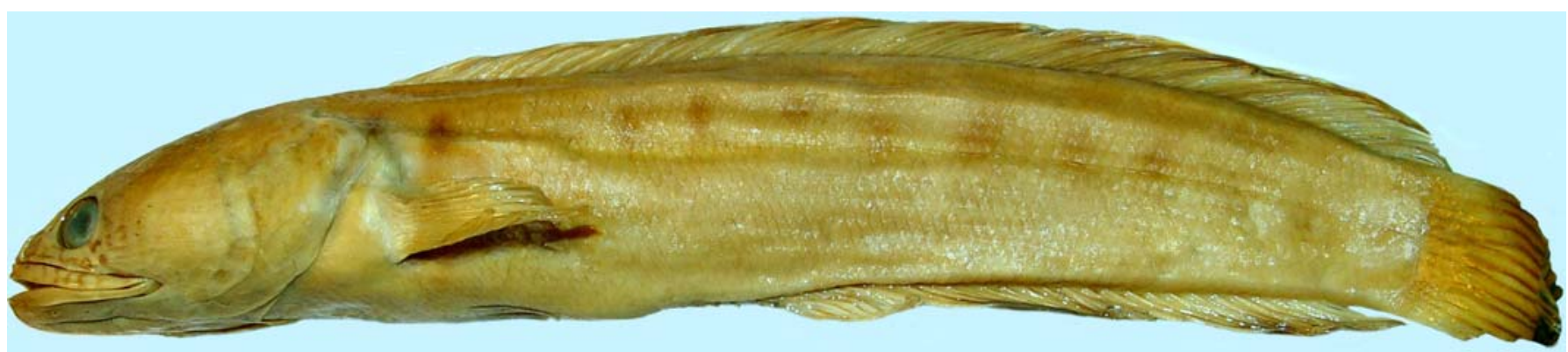

Image 1. Side view of Channa amphibeus (ZSI F 11435/1, 184.6mm SL)

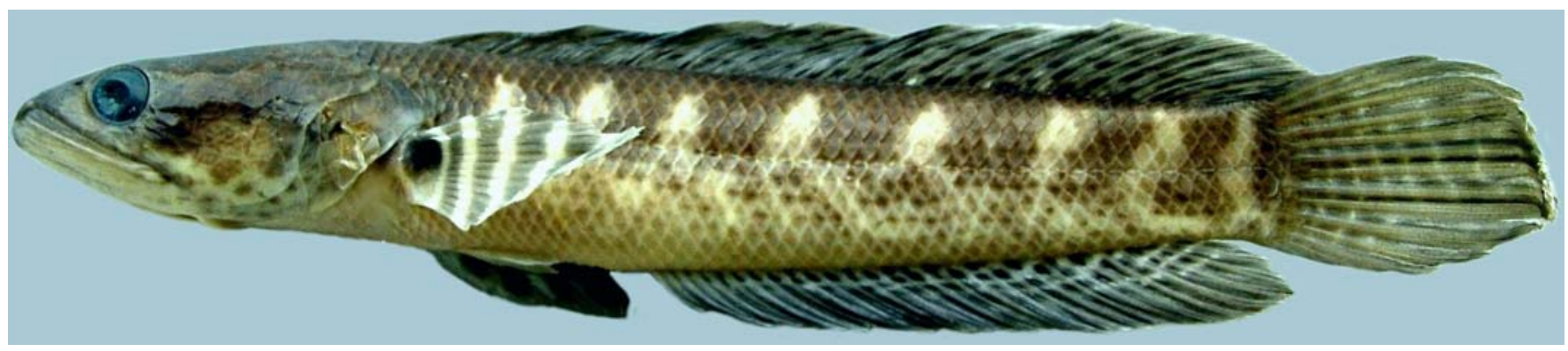

Image 2. Side view of Channa aurantimaculata (GUMF uncat.)

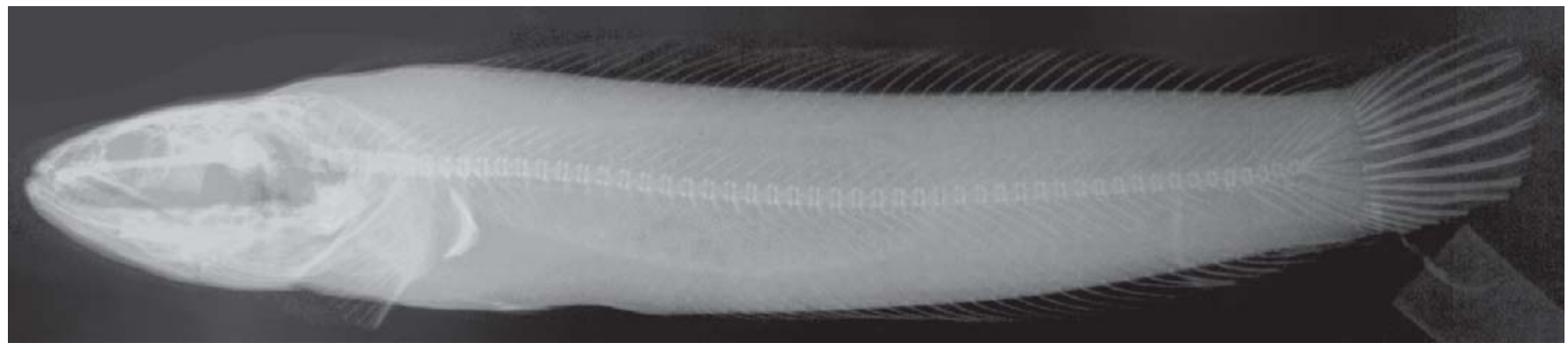

Image 3. Radiograph showing skeleton of Channa aurantimaculata (MUMF-Per/0001, 131.2mm SL)

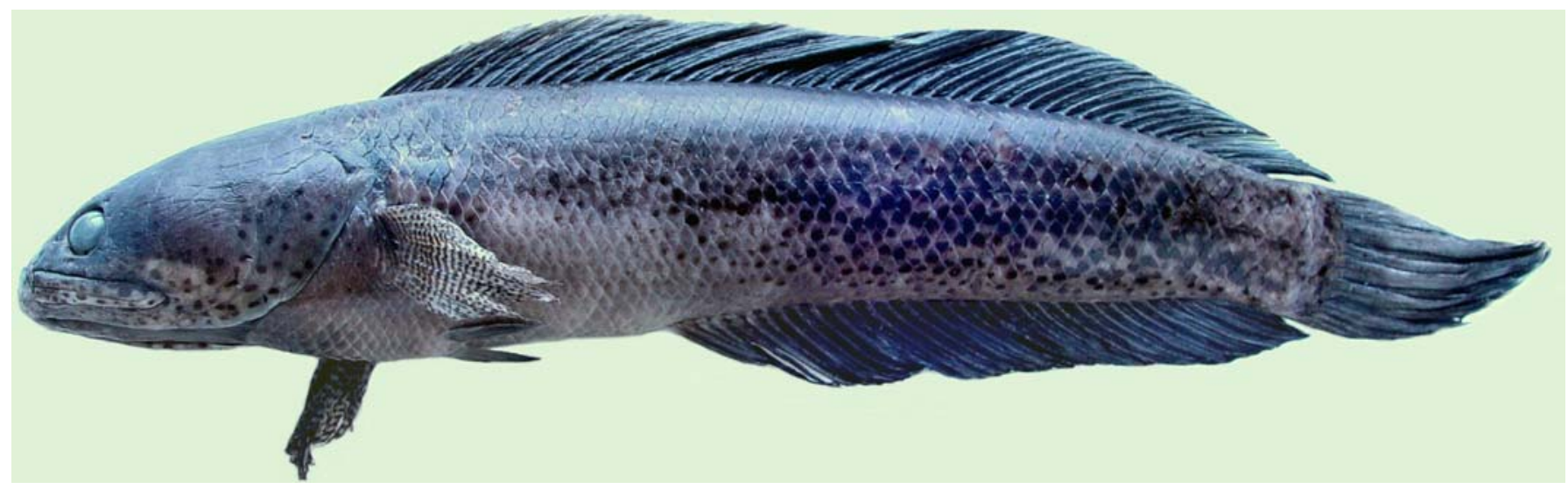

Image 4. Side view of Channa barca (MUMF-Per/0044, 295.0mm SL) 


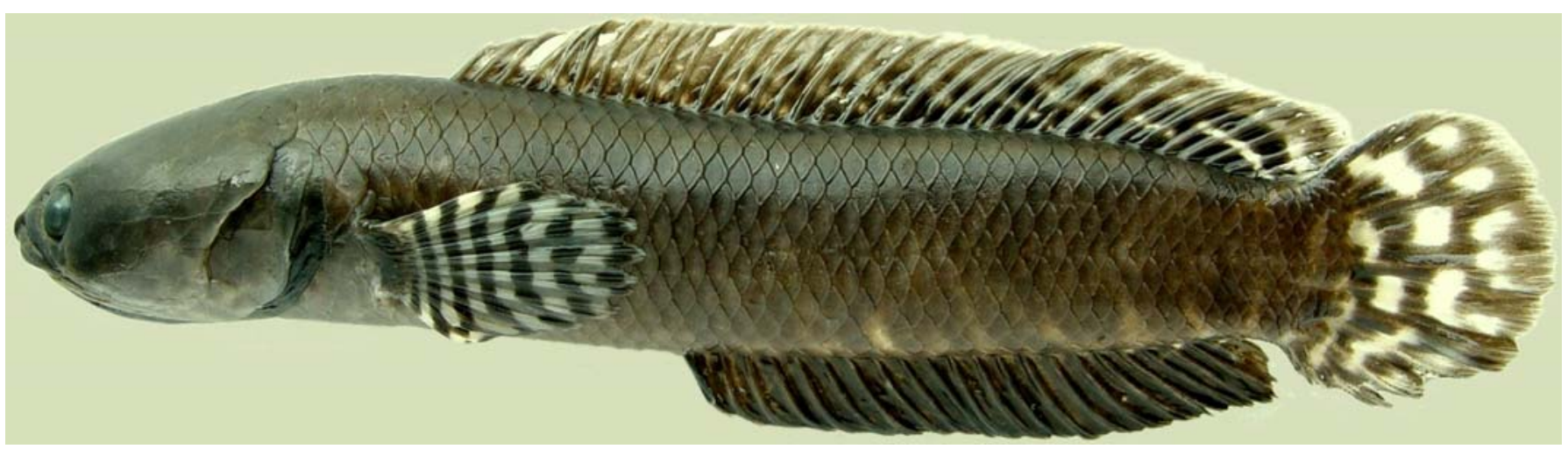

Image 5. Side view of Channa bleheri (GUMF uncat)

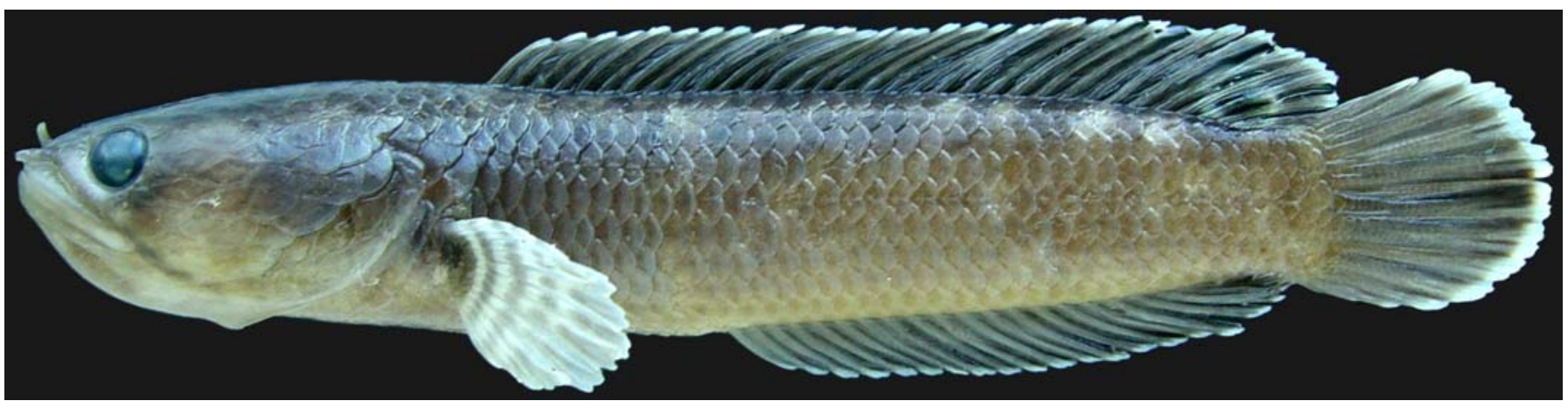

Image 6. Side view of Channa gachua (MUMF uncat., juvenile)

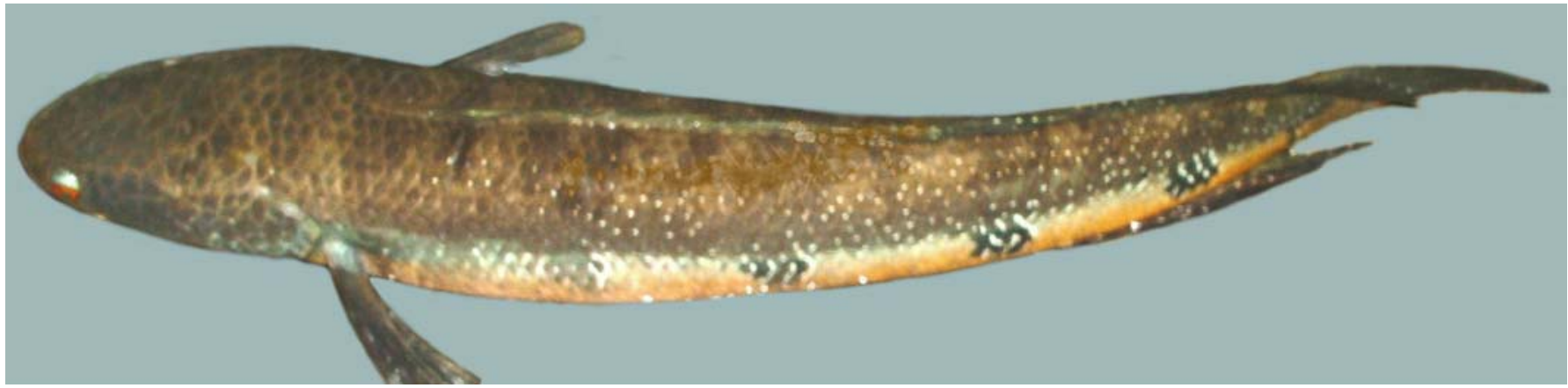

Image 7. Side view of Channa marulius (GUMF uncat)

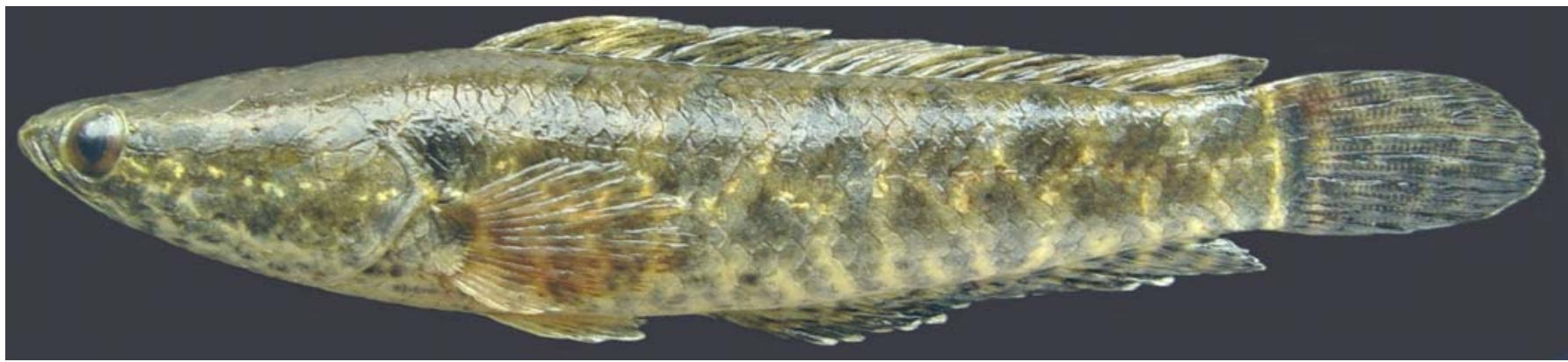

Image 8. Side view of Channa punctatus (GUMF uncat.) 
cephalic sensory pores single, total vertebral count 43 , branchial toothplate count 9 .

Colour: Dorsal, anal and caudal fin margins white. There is often a large ocellus with a light edge on the last five dorsal rays in the young, body black getting lighter ventrally and abdomen creamish.

Remarks: The materials examined agree with the characters of ZSI specimen (ZSI- F- 2705/1), 1 ex, (date unknown), Bulagunj, Sulhet (Sylhet, Bangladesh), 246mm SL.

\section{Channa punctatus (Bloch)} (Image 7)

Ophicephalus punctatus, Bloch, 1793:139 [type locality: no locality].

Materials examined: 8 exs., 3.iii.2004, 95.6-105.9mm SL, Nambul River, Singda, Manipur, India, coll. S. Sanjabihari, MUMF-Per/0013; 3 exs., 29.i.2007, 96.0-101.1mm SL, Teju River, Teju district, Arunachal Pradesh, India, coll. K. Nebeshwar, MUMF-Per/0049.

Distribution: Afghanistan to Myanmar through Sri Lanka Pakistan. Nepal. Bangladesh and Yunnan (China) (Eschmeyer, 2007).

Diagnosis: A species of Channa with scales on cheek 4-6, pelvic fin longer than half pectoral fin length, pectoral fin with no bars, lateral line scales 35-40, dorsal fin rays 28-32, lower jaw with 3-6 canines behind a single row of villiform teeth, anal fin rays 19-21, body with two rows of bars, maxilla and premaxillary processes extending to vertical level of beyond the middle of orbit, sides of lower jaw with one large cycloid scale, cephalic sensory pores single, total vertebral count 35 , branchial toothplate count eight.

Colour: Brown to dark green on flanks, pale yellow ventrally, several dark spots on body.

Remarks: The materials examined agree with the characters of ZSI specimen (ZSI- F-7688/1), 1 ex. from Bhagmati River., Purnea, Champaran, Bihar, India, $144.6 \mathrm{~mm}$ SL.

\section{Channa stewartii (Playfair)}

(Image 8)

Ophiocephalus stewartii, Playfair, 1867:14 (type locality: Cachar, Assam)

Materials examined: 4 exs., 29.i.2007, 102.9-113.5mm SL, Deopani River, Rowing, Lower Devang valley District, Arunachal Pradesh, India, coll. K. Nebeshwar, MUMF-Per/ 002 1; 3 exs., (date unknown), 110.8-112.8mm SL, Assam, India, coll. M.M. Goswami, GUMF uncat.

Distribution: India: Manipur - Barak River (Brahmaputra drainage); Eastern Himalaya, Nepal. (Eschmeyer 2007).

Diagnosis: A species of Channa with small black spots scattered on sides of body, dorsal fin rays $37-41$, and anal fin rays $24-27$, lateral line scales $45-53$, eyes moderate, mouth large, pelvic fin about $1 / 3$ as long as pectoral fin, 4-5 bars on the pectoral fin, head slightly broad with blunt snout, sides of lower jaw with two large cycloid scale, cephalic sensory pores single, total vertebral count 44 , branchial toothplate count seven.

Colour: Light ash to dark brown. Almost all the scales with well defined circular black spots, pectoral fins spotted in zones.

Remarks: They are normally found only in the lower altitudes in the Barak and its tributaries. Often found feeding on young shoots of bamboo plants in swampy areas from rivers.

\section{Channa marulius (Hamilton)}

(Image 9)

Ophicephalus marulius, Hamilton, 1822:65, 367. (type locality: India)

Materials examined: 1 ex., 29.i.2007, $151.6 \mathrm{~mm}$ SL, Teju River, Teju district, Arunachal Pradesh, India, coll. K. Nebeshwar, MUMF-Per/0025; 5 exs., 5.iv.2004, 97.8-151.4mm SL, Chindwin Basin, Moreh, India, coll. Vishwanath and party, MUMF-Per/O026; 5 exs., 19.iii.1999, 488.0mm SL, Barak River, Vanchengphai, Tamenglong district, India, coll. K. Nebeshwar, MUMF uncat.

Distribution: Pakistan in the west through South China, Thailand, Laos and Vietnam (Eschmeyer 2007).

Diagnosis: A species of Channa with a large black ocellus on upper caudal fin base; 3 white spots on body. Dorsal fin rays $50-55$, anal fin rays $31-35$, sides of lower jaws with no scales, lateral line scales 60-70, 4-5 ocelli, presence of a sharp distinct pointed ridge of isthmus and anterior to it many longitudinal striae are present, lower jaw with 7 to 18 canines behind a single row of villiform teeth which deepens to 5 or 6 rows on symphysis, teeth on vomer, cephalic sensory pores not single, total vertebral count 62, branchial toothplate count 16 .

Colour: A well-marked ocellus, brown surrounded by a ring paler than the ground-colour, on the upper half of the base of caudal fin. Five or six dark oval blotches on flank which terminate below lateral line, below lateral line between blotches pale yellow with reddish tinge distinct white spots scattered on body. An orange band running from eye to middle of caudal fin in Juveniles.

Remarks: This species is avoided in culturable waters because of its carnivorous habit. It grows to large size as for instance it has been reported that in Maharashtra this snake head grows up to $180 \mathrm{~cm}$ in length and attains about $30 \mathrm{~kg}$ in weight.

\section{Channa striata (Bloch)} (Image 10)

Ophicephalus striatus Bloch, 1793: 141( type locality: Tranquebar, India)

Materials examined: 8 exs., $21 . i i 1.2007,164.8-187 \mathrm{~mm}$ SL, streams near Imphal valley, Manipur, India, coll. Geetakumari Kh, MUMF-Per/0031; 4 exs., 6.vii.2006, 170.0-185.5mm SL, Gomti River, Barak Basin, Agartala, India, coll. W. Vishwanath, MUMF uncat.; 2 exs., 8.viii.2006, 185.5-186.6mm SL, Ujjain market, Guwahati, India, coll. W. Vishwanath, MUMF uncat.

Distribution: Pakistan in the west through China, Thailand, Malaysia and Indonesia; (Eschmeyer 2007).

Diagnosis: A species of Channa with dorsal fin rays 42-45, anal fin rays 25-29, lateral line scales 55-65, mouth large, and lower jaw 4-7 canines behind a single row of villiform teeth, dorsal and anal fins slightly darker in color than body maxilla and premaxillary process extending to vertical level of beyond posterior margin of orbit, presence of a sharp pointed ridge at the mid-ventral part of isthmus and anterior to it many longitudinal striae are present, cephalic single pores not single, total vertebral count 54, branchial tooth plate count 13 .

Colour: Body with chevron-shaped bars pointing forward, more distinct lower part. Dorsal fin with 5 inter-radial bands on the last 4 rays and $5^{\text {th }}$ to $7^{\text {th }}$ rays has one band at base.

Remarks: The materials examined agree with the characters 


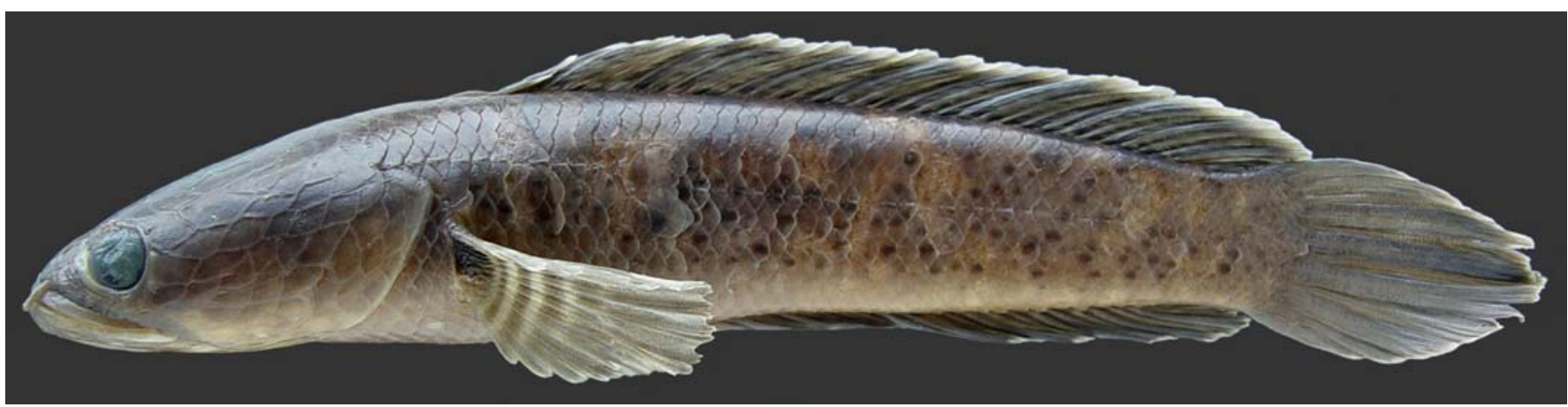

Image 9. Side view of Channa stewartii (MUMF-Per/0021, 102.9mm SL)

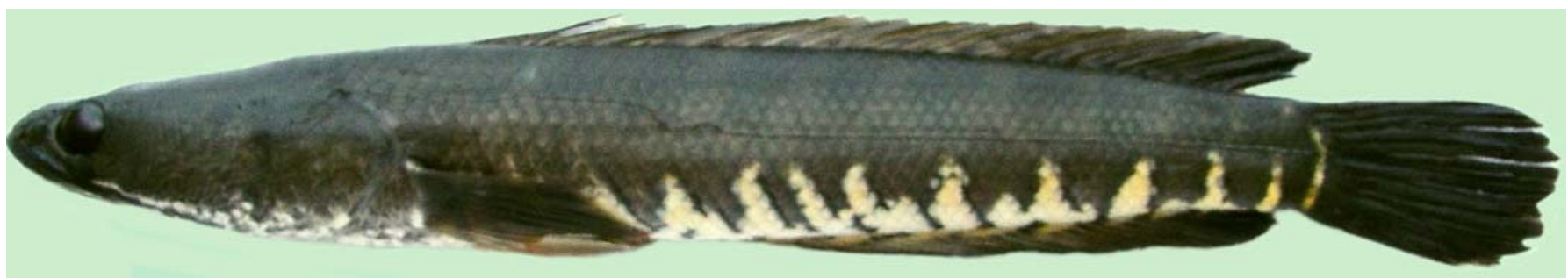

Image 10. Side view of Channa striata (GUMF uncat.)
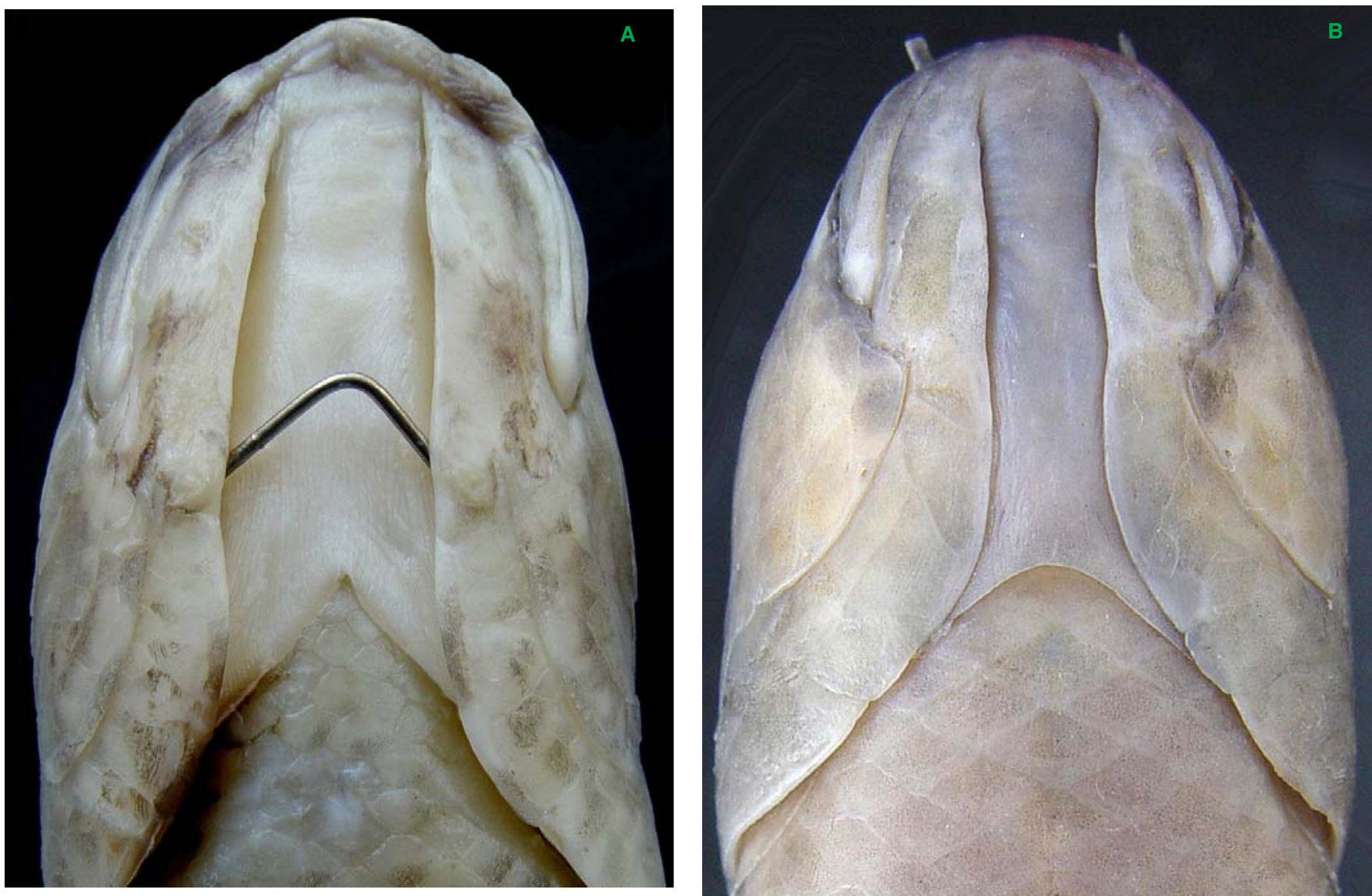

Image 11. a - Channa striata (MUMF-Per/0032,164.8 mm SL), opercula stretched to show V-shaped isthmus; b - Channa gachua (MUMF-Per/0004, $112.8 \mathrm{mmSL}$ ) to show U-shaped isthmus 

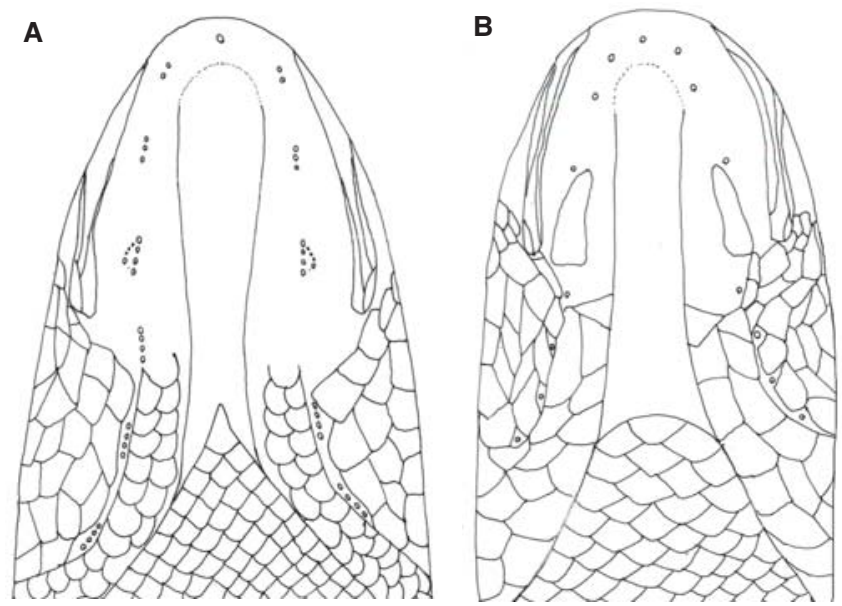

Figure 1. Ventral view of a. Channa marulius and b. Channa gachua showing sensory pores and sides of lower jaw.(MUMF-Per/0025,151.6mm SL) and (MUMF-Per/0004, $112.8 \mathrm{~mm} \mathrm{SL)}$ respectively.
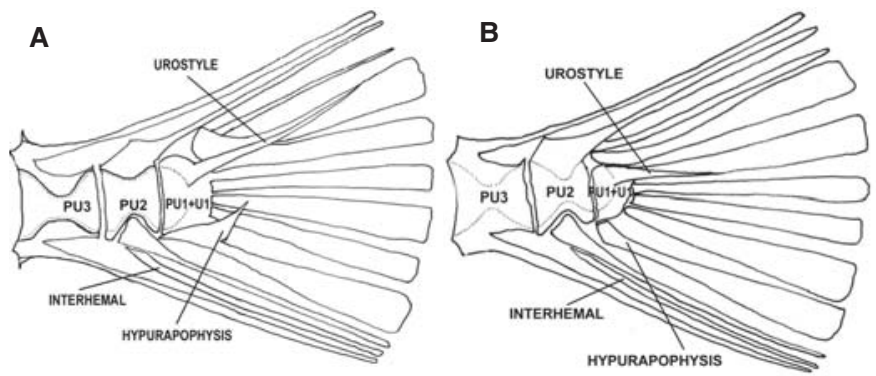

Figure 2. Caudal skeleton of a. Channa marulius (MUMF-Per/ 0025,151.6mmSL) and b. Channa gachua (MUMF-Per/0004, $112.8 \mathrm{mmSL})$

of ZSI specimen (ZSI-F-12922-12923 colletced by Dr. H.S. Preethi from near its type locality, i.e., Cheyyers River near Razampeta, 196.3-247.6 mm SL.

\section{Morphology}

Isthmus: (Image 11) The isthmus is V-shaped, sharp; pointed heading towards the posterior side of the head (in preserved specimen) in marulius group and it is U-shaped in gachua group.
Sensory pores: (Fig. 1) The cephalic sensory pore which is present on the ventral side of the head is in group in case of marulius and it is single in gachua group.

Scales on the lower jaw: (Fig. 1) Scales are absent on the lower jaw of marulius group and one or two pairs of scales are present on each side of the lower jaw of gachua group.

\section{Osteology}

Toothplates: In marulius group 3-4 branchial tooth plates are present in the epibranchial region and the tooth present in this group is very prominent canine and conical like whereas in gachua group only one or no tooth plates are found in the epibranchial region and less prominent compared to the tooth present in the marulius group.

\section{Caudal skeleton: (Fig. 2)}

Hypurapophysis: In marulius group hypurapophysis are very prominent and spine like facing towards the urostyle, and in gachua group hypurapophysis are weakly developed.

"Interhemal spine": In all the species studied, an elongated bone is found between last two hemal spines (PU2 and PU3). The bone is here termed as "interhemal spine".

Urostyle: The urostyle is long and elongated in marulius group whereas in gachua group it is short.

\section{Discussion}

Hora's (1921) list of fishes from Chindwin basin, Manipur included C. harcourtbutleri (Annandale). The species was later synonymised with C. gachua by Hora \& Mukerji (1934). Distribution of C. harcourtbutleri in Manipur, India is doubtful. While resurrecting synonymy of the species with C. gachua, $\mathrm{Ng}$ et al. (1999) reported the species to be distributed in Inle lake, Mynamar only. Sen's (1985) list of Channa of northeastern India included $C$. orientalis which is distributed in Sri Lanka only. Courtenay et al. (2004) clearly noted that $C$. orientalis is endemic to Sri Lanka which has been always confused with C. gachua.

While examining Channa gachua from different parts of South and Southeast Asia, Ng et al. (1999) observed many small black spots on the body of Indochinese specimens but not in those of Indian and Sundaic specimens. They suspected

\section{Key to species of genus Channa of north-east India}

1. $\quad$ - shaped sharp isthmus, cephalic sensory pores arranged in groups .................................................. 8

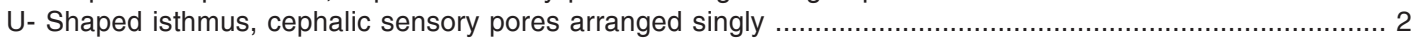

2. Pelvic fin present, tooth plates present on both sides of the first gill arch ................................................. 3 Pelvic fin absent, tooth plates present only on the outer side of the first gill arch .......................... C. bleheri

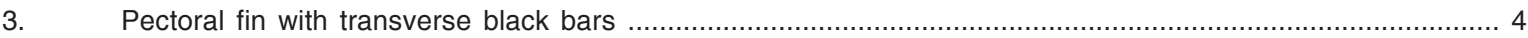

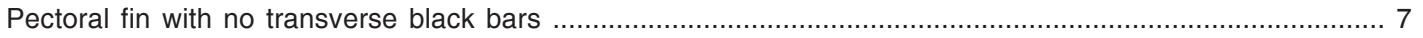

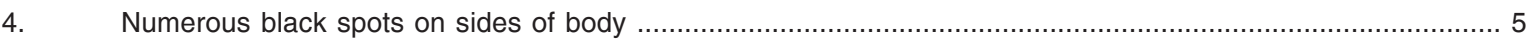

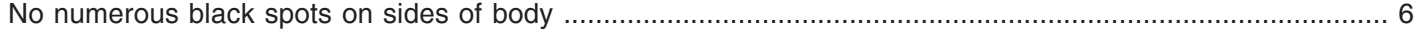

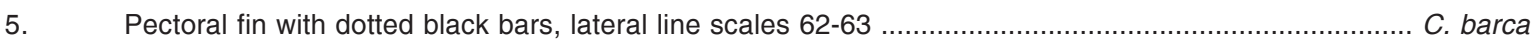

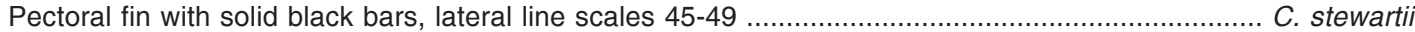

6. 7-8 large irregular bars on upper half of body, lateral line scales $52-54$............................ C. aurantimaculata

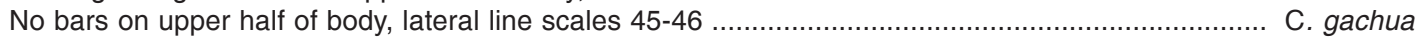

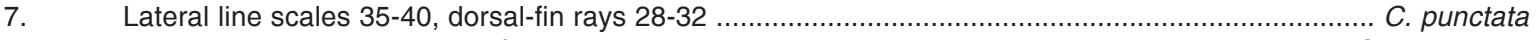

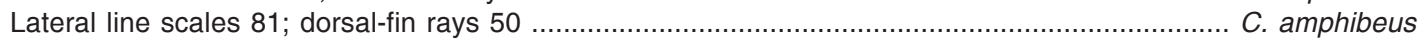

8. Presence of ocellus on the caudal fin, $4-5$ ocelli on sides of the body ............................................ C. marulius No ocellus on the caudal fin, body with chevron-shaped bars pointing upward .................................. C. striata 
Table 1. Morphological characters of Channa species (\% SL, except SL in $\mathrm{mm}$ ) under study

(1 - C. amphibeus; 2 - C. aurantimaculata; 3 - C. barca; 4 - C. bleheri; 5 - C. gachua; 6 - C. marulius; 7 - C. punctatus; 8 - C. striata; 9 - C. stewartii)

\begin{tabular}{|c|c|c|c|c|c|c|c|c|c|}
\hline Characters & 1 & 2 & 3 & 4 & 5 & 6 & 7 & 8 & 9 \\
\hline $\mathrm{N}$ & 1 & 5 & 4 & 2 & 11 & 11 & 11 & 14 & 7 \\
\hline Standard length & 184.6 & 121.9-131.2 & 295- 297 & $148.4-149.1$ & $112.8-246$ & $97.8-151.6$ & $95.6-144.0$ & $164.8-187.0$ & $102.9-113.5$ \\
\hline Body depth & 17.6 & $13.5-17.02$ & $15.03-17.32$ & $17.1-17.6$ & $18.06-18.8$ & $16.4-16.9$ & $19.5-21.9$ & $15.7-16.7$ & $16.42-18.3$ \\
\hline Head length & 27.6 & $28.6-28.9$ & $20.98-23.76$ & $25.2-25.9$ & 28.9-30.05 & $29.7-31.4$ & $35.4-35.9$ & $32.5-32.9$ & 29.9-31.3 \\
\hline Head depth at nape & 50.4 & $43.8-47.01$ & $60.1-61.1$ & $61.1-62.4$ & $56.04-60.2$ & $42.34-43.24$ & $52.9-53.5$ & $41.7-41.9$ & $46.6-55.7$ \\
\hline Head depth at eye & & $28.7-34.5$ & $34.8-34.9$ & $34.3-36.8$ & $33.6-36.3$ & $23.1-24.6$ & $31.3-34.1$ & $28.03-28.8$ & $31.6-33.3$ \\
\hline Head width(max) & 59.6 & $62.2-69.02$ & $58.6-58.8$ & $75.2-76.1$ & $65.5-70.0$ & $50.5-56.3$ & $56.4-59.4$ & $49.7-53.4$ & $63.5-68.8$ \\
\hline Head width(eye) & & $50.9-52.9$ & $45.7-46.0$ & $50.19-51.03$ & $45.4-48.9$ & $39.9-40.7$ & $37.6-41.2$ & $38.4-41.4$ & $46.7-51.03$ \\
\hline Snout length & 22.0 & $23.9-24.7$ & $19.6-19.9$ & $24.10-25.13$ & $24.2-27.2$ & $20.5-22.2$ & $19.1-20$ & $20.9-21.3$ & $23.9-25.07$ \\
\hline Eye diameter & 14.7 & $14.9-15.06$ & $11.92-12.75$ & $13.2-13.5$ & $15.04-17.4$ & $13.7-19.2$ & $13.7-15.9$ & $12.2-12.8$ & $15.8-18.08$ \\
\hline Interorbital space & 23.5 & $34.9-36.9$ & $28.30-33.33$ & $38.3-39.4$ & $36.5-38.2$ & $29.5-30.6$ & $26.6-29.5$ & $28.9-31.8$ & $33.6-35.7$ \\
\hline Dorsal fin base length & 75.0 & $59.4-63.6$ & $67.90-70.68$ & $63.4-64.4$ & $58.25-61.6$ & $59.7-61.7$ & $50.9-56.3$ & $53.5-56.4$ & $57.7-63.1$ \\
\hline Pectoral fin length & 16.8 & $16.7-19.36$ & $15.40-15.59$ & $17.3-17.4$ & $17.5-20.12$ & $14.2-14.9$ & $18.8-21.9$ & $16.7-17.33$ & $17.5-19.9$ \\
\hline Ventral fin length & 5.6 & $8.08-8.24$ & $6.70-6.80$ & Absent & $8.15-9.8$ & $10.5-14.2$ & $14.16-15.06$ & $12.14-13.7$ & $7.9-9.93$ \\
\hline Anal base fin length & 46.6 & $39.8-39.9$ & $42.72-44.23$ & $40.1-41.4$ & $36.5-43.7$ & $37.5-39.4$ & $38.7-42.2$ & $32.9-36.4$ & $39.7-40.8$ \\
\hline Upper jaw length & 48.4 & $41.5-48.09$ & $45.69-55.8$ & $46.2-47.4$ & $38.6-42.2$ & $42.6-43.9$ & $34.2-36.8$ & $44.09-44.5$ & $42.2-43.7$ \\
\hline Lower jaw length & 47.4 & $44.6-48.6$ & $46.6-46.9$ & $47.4-48.7$ & $46.18-46.3$ & $32.2-33.2$ & $41.5-44.4$ & $45.9-46.9$ & $41.5-48.1$ \\
\hline Pelvic to anal distance & 14.3 & $12.9-14.3$ & $14.1-14.9$ & & $15.9-18.9$ & $22.3-25.4$ & $14.2-19.7$ & $16.22-17.9$ & $14.8-16.12$ \\
\hline Scales in transverse. Row & & $15 \frac{1}{2}-161 / 2$ & $151 / 2$ & $11 \frac{1}{2}$ & $11 \frac{1}{2}-13 \frac{1}{2}$ & $21 \frac{1}{2}-221 / 2$ & $13 \frac{1}{2}-14 \frac{1}{2}$ & $181 / 2$ & $131 / 2-14 \frac{1}{2}$ \\
\hline Dorsal fin rays & 50 & $45-47$ & $50-51$ & 37 & $32-37$ & $50-55$ & $28-32$ & $42-45$ & $37-41$ \\
\hline Pectoral fin rays & 15 & $14-16$ & $15-16$ & 14 & 17 & 17 & $15-16$ & $17-18$ & 16 \\
\hline Anal fin rays & 35 & $28-30$ & $33-34$ & 25 & $21-27$ & $31-35$ & $19-21$ & $25-29$ & $24-27$ \\
\hline Caudal fin rays & & 15 & 13 & 14 & 12 & 14 & 15 & 15 & 14 \\
\hline Lateral line & 81 & $51-54$ & $62-63$ & $46-50$ & $39-48$ & $60-70$ & $35-40$ & $55-65$ & $45-53$ \\
\hline Vertebrae & & 51 & 56 & 43 & 43 & 62 & 35 & 54 & 44 \\
\hline
\end{tabular}

involvement of more than one species. As Hamilton (1822) described the species from northern Bengal, which belongs to Ganga drainage, the specimens under the present study, which is within the range of its natural distribution, should be $C$. gachua sensu stricto. The specimens from Manipur also agree with the description of Brahmaputra specimens.

The morphological and osteological comparison of the present 9 species of Channa examined indicates that they constitute 2 phylectic groups each consisting of species sharing these morphological features almost completely. The two groups are marulius group and gachua group. The marulius group comprises of C. marulius and C. striata and gachua group comprises of C. amphibeus, C. aurantimaculata, C. barca, C. bleheri, C. gachua, C. punctatus and C. stewartii. The morphological similarity as seen among species in each group is sufficient to suggest that members of the same group are descendents from a common direct ancestral stock.

Morphologically the members of the marulius group is differentiated from the gachua group in having a prominent Vshaped sharp isthmus, grouped sensory pores arrangement, absence of big cycloid scales on the lower jaw whereas the members of gachua group have U-shaped isthmus, single sensory pores arrangement, presence of one or two big cycloid scales on each side of the lower jaw.

Gill rakers are absent in Channid fishes studied. Instead, branchial tooth plates are present on the gill arches Greenwood (1976). The number of tooth plates ranges from 5-16 in different Channid species. Marulius group has 3-4 numbers of branchial tooth plates in the epibranchial, presence of a prominent spine shaped hypurapophysis in the parhypural and presence of an elongated urostyle whereas the members of the gachua group has one or no branchial tooth plates in the epibranchial region, no spine shaped hypurapophysis and presence of a short urostyle. Tooth plates count are highest in marulius group.

Although C. bleheri is included in the gachua group, the species does not have pelvic fin. Another very significant character of the species is that tooth plates are present only on the outer side of the first gill arch and absent on the inner side of the same arch. Examination of more specimens would come out with interesting results.

In caudal skeleton of the genus studied, the last three caudal vertebrae support the caudal fin. The last fused centrum bears one parhypural, five hypural plates, one urostyle and one epural. The epural bone is thin, backwardly curved and located anteriorly to the urostyle. An elongated bone which has no connection with any of the centrum is present between the hemal spine of preuralcentrum 2 and preuralcentrum 3 (i.e anterior to parhypural). Distal tip of this bone supports the caudal-fin ray ventrally. The bone is referred as "interhemal spine". The presence of interhemal spine is a very specific character found in all the species of Channa under study. The illustration of Day (Plate IC, 1909) also have the interhemal spine however, he treated it as hypural.

\section{References}

Courtenay, J., R. Walter and D. W. James. (2004). Channa gachua Snakeheads (Pisces, Channidae) - A Biological Synopsis and Risk Assessment. U.S. Department of the Interior, U.S. Geological Survey. USGS Circular 1251

Day. A.L. (1909). The osseous system of Ophiocephalus striatus Bloch. Proceedings of Washington Academy of Science 507(3): 19-59.

Dehadrai, P.V. (1975). Derelict waters for Air- Breathing fish culture. Indian Farming 19-23.

Eschmeyer, W. (2007). Catalog of Fishes. www.calacademy.org/research/ ichthyology; updated on October 9, 2007, accessed on November 30,2007

Goswami, M.M., B. Arunav \& P. Janardan (2006). Comparative biometry, habitat structure and distribution of endemic snakehead (Teleostei: Channidae) species of Assam, India. Journal of the Inland Fisheries 
Society of India 38(1): 1-8.

Greenwood, P.H. (1976). A review of the family centropomidae (Pisces, Perciformes). Bulletin of the British Museum (Natural History) 29(1): 1-81.

Hamilton, F. (1822). An Account of the Fishes Found in the River Ganges and Its Branches. Archibald Constable and Company, London, 405pp + 39pls.

Hollister, G. (1934). Clearing and dyeing fish for bone study. Zoologica 12: 89-101.

Hora, S.L. (1921). Fish and fisheries of Manipur with some observations on those of the Naga Hills. Records of Indian. Museum 22: 165-214.

Hora, S.L. \& D.D. Mukerji (1934). Notes on fishes in the Indian Museum. XXIL On a collection of fish from the S. Shan States and the Pegu Yomas, Burma. Records of Indian Museum 36: 125-138.

Kullander, S.O. \& R. Britz (2002). Revision of the family Badidae (Teleostei: Perciformes), with description of a new genus and 10 new species. Ichthyological Exploration of Freshwaters 13(4) 295-372.

Menon, M.A.S. (1952). On a small collection of fish from Manipur. Records of the Indian Museum 50: 265-270.

Menon, A.G.K. (1954). Further observations on the fish fauna of the Manipur State. Records of Indian Museum 52(1): 21-26.

Musikasinthorn, P. (2000). Channa aurantimaculata, a new Channid fish from Assam (Brahmaputra River Basin), India, with designation of a neotype for C. amphibeus (McClelland, 1845). Ichthyological Research 47(1): 27-37.

Ng, H.H., P.K.L. Ng \& R. Britz (1999). Channa harcourtbutleri (Annandale, 1918): a valid species of snakehead (Perciformes: Channidae) from Myanmar. Journal of South Asian Natural History 4: 576.

Sen, T.K. (1985). The fish fauna of Assam and the neighbouring northeastern states of India Occassional Paper, Records of the Zoological Survey of India 64: 216

Shaw, G.E. \& E.O. Shebbeare (1937). The fishes of Northern Bengal. Journal of Royal Asiatic Society of Bengal (Science): $137+6$ pls

Talwar, P.K. \& A.G. Jhingran (1991). Inland Fishes of India and Adjacent Countries. Oxford and IBH Publishing Co. Pvt. Ltd., New Delhi, 2 volumes: xix +1158 pp.

Vierke, J. (1991). Ein farbenfroher neuer Schlangenkopffisch aus Assam Channa bleheri spec. nov. Das Aquarium 259: 20-24.

Vishwanath, W. (2000). Fish Fauna of Manipur. Manipur Association for Science and Society, 137pp + vi pls.

Vishwanath, W. (2002). Fishes of North East India, A Field Guide to Species Identification. Manipur University and NATP, 198pp.
Author Details:

W. Vishwanath is a Professor in the Department of Life Sciences, Manipur University. His field of specialization is Fish and Fisheries. He is at present engaged in taxonomy and systematics of freshwater fishes of northeastern India. $\mathrm{KH}$. Geetakumari is a research scholar in the Department of Life Sciences, Manipur University. She is pursuing research in Phylogenetic studies of fishes belonging to the order Perciformes found in northeastern India under the supervision of Prof. W. Vishwanath.

\section{Author contribution:}

W. VishWANATH The study: Supervision of taxonomy and phylogeny of freshwater fishes of northeastern India. Current paper: Supervised the work and helped in identifying the species. KH. GeetakumarI The study: Undergoing research in the Perciformes fishes of northeastern India. Current paper: As a part of the research work, all the channid fishes of the region has been collected and identified. The paper is a part of the results. 